\title{
A Rfid Based Attendance Tracking System
}

\begin{abstract}
Sahoo. P
Abstract: "A RFID BASED ATTENDANCE TRACKING SYSTEM" is designed to collect and manage employee attendance records from RFID devices installed in an enterprise environment. Based on the verification of employee identification at the entrances, the system could generate sophisticated employee attendance data for analysis purposes. It is also designed to automate their offices. Office automation is based on personalized profiles. Profiles can be edited on the run time without making any changes in the hardware. The database software is smart enough to mark the attendance if and only if the card holder spent a minimum time required for attendance in office.
\end{abstract}

Keyword: RFID Reader, RFID Tags, Microsoft SQL Server, Security, AUTHENTICATION.

\subsection{OVERVIEW :-}

\section{Introduction}

Radio-frequency identification (RFID) is an automatic identification method, relying on storing and remotely retrieving data using devices called RFID tags or transponders. The technology requires some extent of cooperation of an RFID reader and an RFID tag.

An RFID tag is an object that can be applied to or incorporated into a product, animal, or person for the purpose of identification and tracking using radio waves. Some tags can be read from several meters away and beyond the line of sight of the reader.

\section{OBJECTIVE:-}

The aim of the project is to design a system that have a small coverage area and can be use for authentication or identification purposes. "RFID based Smart Office" is a system that uses RFID technology to maintain the attendance at real-time that can be monitored on Database server (PC). In addition the system also supports the room automation (automatic control of doors and lights).

\subsection{BACK GROUND :-}

RFID has established itself in a wide range of markets including livestock identification systems because of its ability to track moving objects.

\section{* RFID TAGS:-}

Tags also sometimes are called "transponders". RFID tags can come in many forms and sizes. Some can be as small as a grain of rice. Data is stored in the IC and transmitted through the antenna to a reader. The two commonly used RFID Transponders are Active (that do contain an internal battery power source that powers the tags chip) and Passive (that do not have an internal power source, but are externally powered typical from the reader) RFID Transponders.

\section{RFID READER:-}

A reader (now more typically referred to as an RFID interrogator) is basically a radio frequency (RF) transmitter and receiver, controlled by a microprocessor or digital signal processor. The reader, using an attached antenna, captures data from tags, then passes the data to a computer for processing. The reader decodes the data encoded in the tag(s) integrated circuit (silicon chip) and the data is passed to the host computer for processing.

\subsection{WORKING OF RFID:-}

Information is sent to and read from RFID tags by a reader using radio waves. In passive systems, which are the most common, an RFID reader transmits an energy field that "wakes up" the tag and provides the power for the tag to respond to the reader. Data collected from tags is then passed through communication interfaces (cable or wireless) to host computer systems in the same manner that data scanned from bar code labels is captured and passed to computer systems for interpretation, storage, and action.

\subsection{FREQUENCIES OF RFID:-}

RFID deployments tend to use unlicensed frequencies for their obvious cost benefits. 
There are four commonly used frequencies:

- Low frequency (LF) 125/134.2 KHz.

- High frequency (HF) $13.56 \mathrm{MHz}$

- Ultra high frequency (UHF) (including 869 and $915 \mathrm{MHz}$ ).

- Microwave (at $2450 \mathrm{MHz}$, a band familiar to ISPs).

A tag's read range performance is usually considered the primary gauge of its suitability for a particular application. It is important to remember that not all applications require maximum range. Tags in the LF-HF band have a range of 1 to 18 inches, while passive UHF tags can reach up to 20 feet, and microwave tags can reach 1 to 6 feet. The ranges greatly depend upon the surface on which the tag is mounted.

\section{Indentations And Equations}

MODULES

- REGISTRATION MODULE

- FINGER PRINT EMBEDDING MODULE

- TID CRYPT ANALYSIS MODULE.

- TRANSANCTION MODULE.

- AUTHENTICATION MODULE

- VERIFICATION MODULE

\section{REGISTRATION MODULE}

The purpose of the registration module is to get the user's details such as Name, Finger Print and other relevant information in order to include the person successfully in the database as an authorized/ authenticated user to carry on further processes of the application i.e. transaction. Only after finishing the registration, a person can logon to the system to perform transactions say view balance, withdrawal, etc.

The registration module is classified into two parts they are as followings:-

1. Employee/Staff registration module

2. Student registration module.

Employee/Staff registration module:- The main purpose of staff registration is get the information about the staff during the registration process which is going to be stored in the database. The information taken by the staff like finger print and pin code is stored in the database for the future use. After the registration the staff a RFID card is given to the staff, which contain all the information about the staff. The card secret number is encrypted before storing in the database for the security purpose.

When the staff try to login the RFID reader try to match the information based on the RFID card number. If all the details are matched with tat car number then the staff is logged on. Student registration module:- The main purpose of student registration is get the information about the student during the registration process which is going to be stored in the database. The information taken by the student like finger print and pin code is stored in the database for the future use. After the registration the student a RFID card is given to the student, which contain all the information about the staff.

The card secret number is encrypted before storing in the database for the security purpose. When the student try to login the RFID reader try to match the information based on the RFID card number. If all the details are matched with tat car number then the student is logged on. In the Student we are providing photo on the RFID card to act as a proof of the particular student. The student RDIF card will not help them on for Attendance but the same card will act as key for library entry and taking of book from there without any paper work. So, by using this RFID card we are not making the work as computerized but also make it fast to save time.

\section{FINGER PRINT EMBEDDING MODULE}

In this module, User's security is focused i.e. the user's Finger Print given at the time of registration is embedded on a fake image. The Finger Print is not stored as such in database instead it is strongly encrypted. The original Finger Print image has been split into three parts and then the fake image is embedded on it. This fake image is encrypted and stored in database. So this makes the user data to be in safer side. Hence, even when the hacker hacks the database and tries to get the user's details, the hacker will end up with fake one. Because the database contains the encrypted form of fake images embedded on the original image. Thus security is enhanced. The main purpose of taking finger print from the use is to provide the security at the time of logging.

The finger print we are taken at the time of registration is encrypting with the other duplicate finger print ad then stored in the database. So, If in case our database is hacked then the hacker is confuse within the 
two finger prints. After the card shown in the front of RFID card reader the finger print is asked for the authentication purpose.

\section{TID CRYPT ANALYSIS MODULE}

In this module, the financial Organization's security is focused i.e. card holder is allowed to give a pin number along with the exposure of RFID card. The TID is also a 16 bit value but it will be in Manchester code format. These values which are the user's input unique to each customer/card holder is safely stored in database as encrypted form. The encryption performed is a strong encryption scheme i.e. The first 8 bit of RFID TID encryption scheme is applied to encrypt the concatenated bits, say X encryption scheme. Secondly the next 8 bit of RFID TID a different encryption scheme is performed say ' $\mathrm{Y}$ ' to encrypt them. TID crypt analysis module is use only for encrypting purpose at the time of store information in the database.

RFID card number is encrypted in two form the first 8 bit is encrypted with different algorithm and other 8 bit is encrypted with different algorithm. The result of the algorithm is the added and forms the output. The output is added in the data base. So, in case the database is hacked the the hacker get confused with RFID card number.

\section{AUTHENTICATION MODULE}

Authentication is any process by which you verify that someone is who they claim they are. This usually involves a username and a password, but can include any other method of demonstrating identity. In this project the Finger Print and pin number is used for authentication. During the authentication, the user have to give the Finger Print and pin number. This will be done by the authentication module by interacting with the verification module. In Authentication process we are providing authentication to the Staff and user by demonstrating their identity. Authentications carried out in two ways:-

1. Finger print

2.pin code/password

Finger print, in this when the use shows the RFID card in front of the RFID reader. Then the reader is ask for the finger print to provide the authentication. If the finger print is matched with finger print stored in the database the Staff is logged in. Else authentication is restricted. Pin code in this when the use shows the RFID card in front of the RFID reader. Then the reader is ask for the pin code to provide the authentication. If the pin code is matched with pin code stored in the database the Staff is logged in. Else authentication is restricted.

\section{VERIFICATION MODULE}

In this verification module, the user's Finger Print will be compared with the Finger Print image given at the time of registration. The retrieval of the original Finger Print image from the database involves the reverse process of embedding i.e. vice versa. If the given user's Finger Print and the pin number is valid, the user is allowed to perform the next process else the user is allowed to exit the system. After verifying both the user's inputs, the user will be allowed to perform transactions. The verification module perform the verification during the loggin process. This module verify the user input with the information stored in the database. If the input is matched then user is allowed to perform operation else user is restricted. The verification is carried by the finger print or by pin code. It is nothing but the comparison during the login process.

\section{TRANSANCTION MODULE}

Transaction module is used to perform user's processes such as Student Attendance and Staff Attendance. Employee/staff Attendance, After the authentication and verification process over successfully. The employee is allowed to perform their loggin operation. Then the employee is marked present for whole day until the again show the card at the time of leaving. Again when the user show the card then this the user performed as logout. The loggin and logout time is stored in data base for the further use. So, by using the RFID we can automate the information related to card holder. Student Attendance, After the authentication and verification process over successfully. The student is allowed to perform their login operation . Then the student is marked present for whole day until the again show the card at the time of leaving. Again when the student show the card then this the user performed as logout. The login and logout time is stored in data base for the further use. So, by using the RFID we can automate the information related to card holder. 
I. FigURES AND TABLES

ADMIN TABLE:-

\begin{tabular}{|l|l|l|l|}
\hline S. NO & \multicolumn{1}{|c|}{ FIELD NAME } & DATA TYPE & DESCRIPTION \\
\hline 1 & User Name & Text & Store user name for checking Correct username \\
\hline 2 & Password & Text & Store password corresponding to username \\
\hline 3 & User Type & Text & User Type Administrator or User \\
\hline
\end{tabular}

EMPLOYEE TABLE:-

\begin{tabular}{|l|l|l|l|}
\hline S. NO. & FIELD NAME & DATA TYPE & DESCRIPTION \\
\hline 1 & Employee id & Number & Unique key for Every Teacher \\
\hline 2 & Employee Name & Text & Name of Employee \\
\hline
\end{tabular}

ATTENDANCE TABLE:-

\begin{tabular}{|l|l|l|l|}
\hline S.NO. & FIELD NAME & DATA TYPE & DESCRIPTION \\
\hline 1 & Employee name & Text & Name of Employee \\
\hline 2 & Status & Number & $\begin{array}{l}\text { Total number classes attended by particular } \\
\text { Student }\end{array}$ \\
\hline 3 & Department & Text & In which department he/she working \\
\hline 4 & Time & Number & Entry timing \\
\hline 5 & Month & Text & $\begin{array}{l}\text { The Month Wise Attendance is maintained where total } \\
\text { working days in month=20 }\end{array}$ \\
\hline
\end{tabular}

\section{SCREEN SHOTS}

\section{Login Form :-}

Only Admin can login here with the use of Login id and unique password.

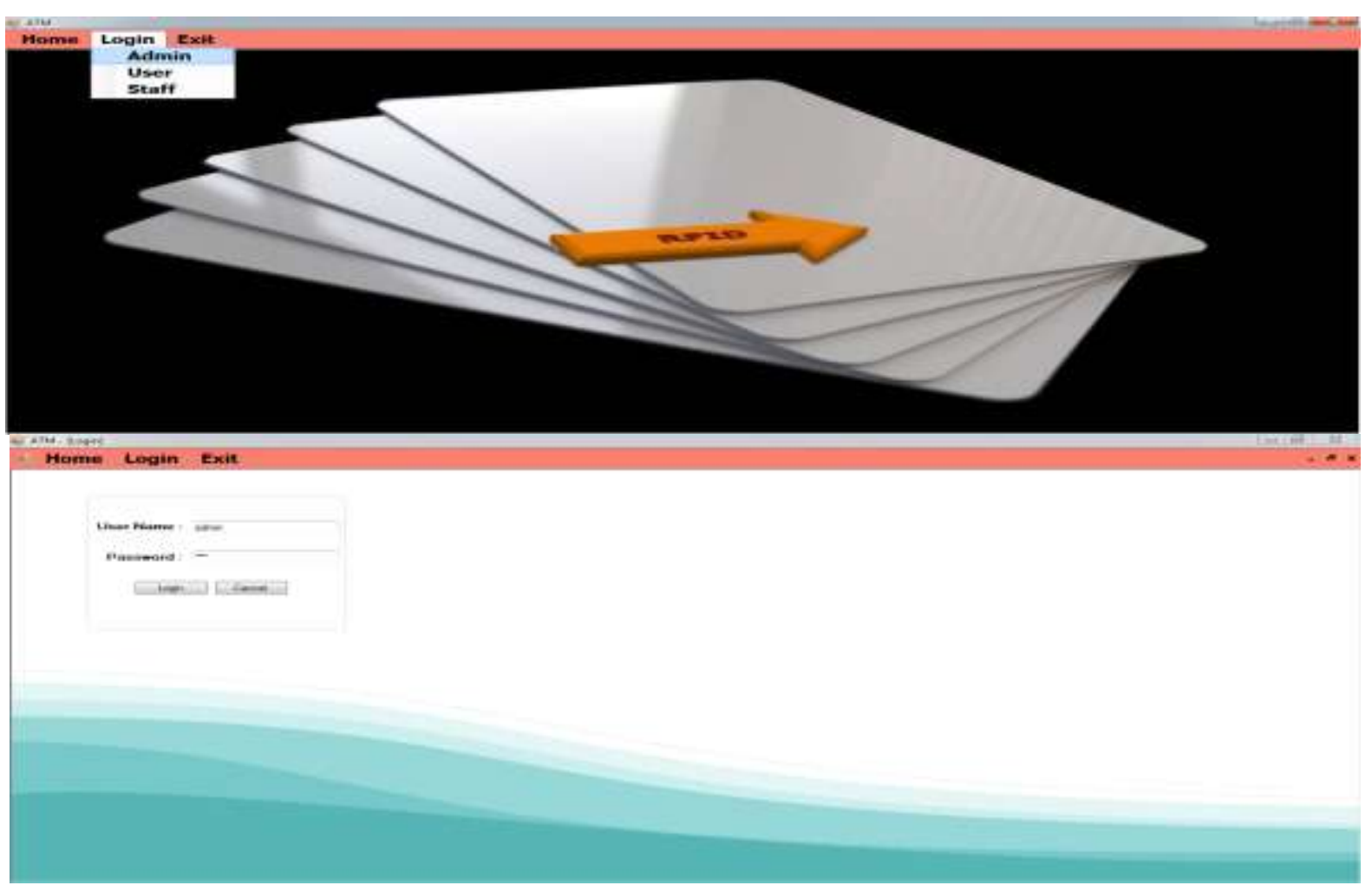

Staff Registration :-

After login the page, we will open the Register where three option are there. First we will open Staff Details for new Registration form of new Staff. 


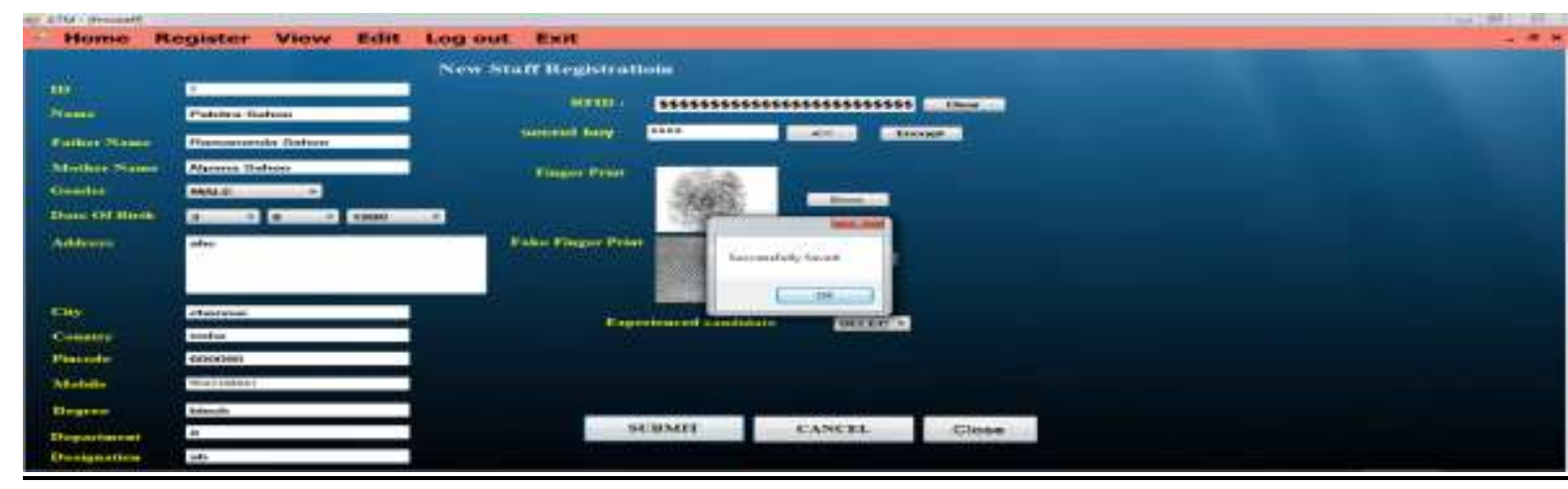

\section{Staff Details :-} conformation.

After completing your staff registration, if you want you can check the data base for

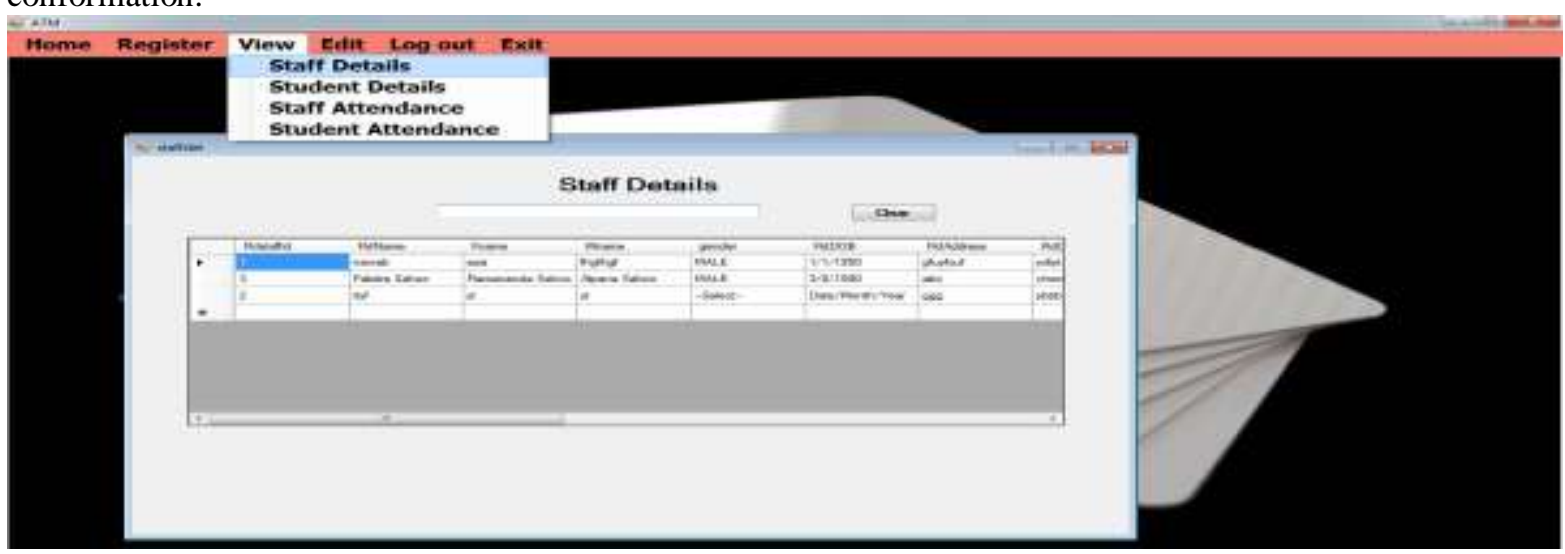

\section{Staff Attendance Details :-}

If you want to check staff attendance percentage or time in and time out.
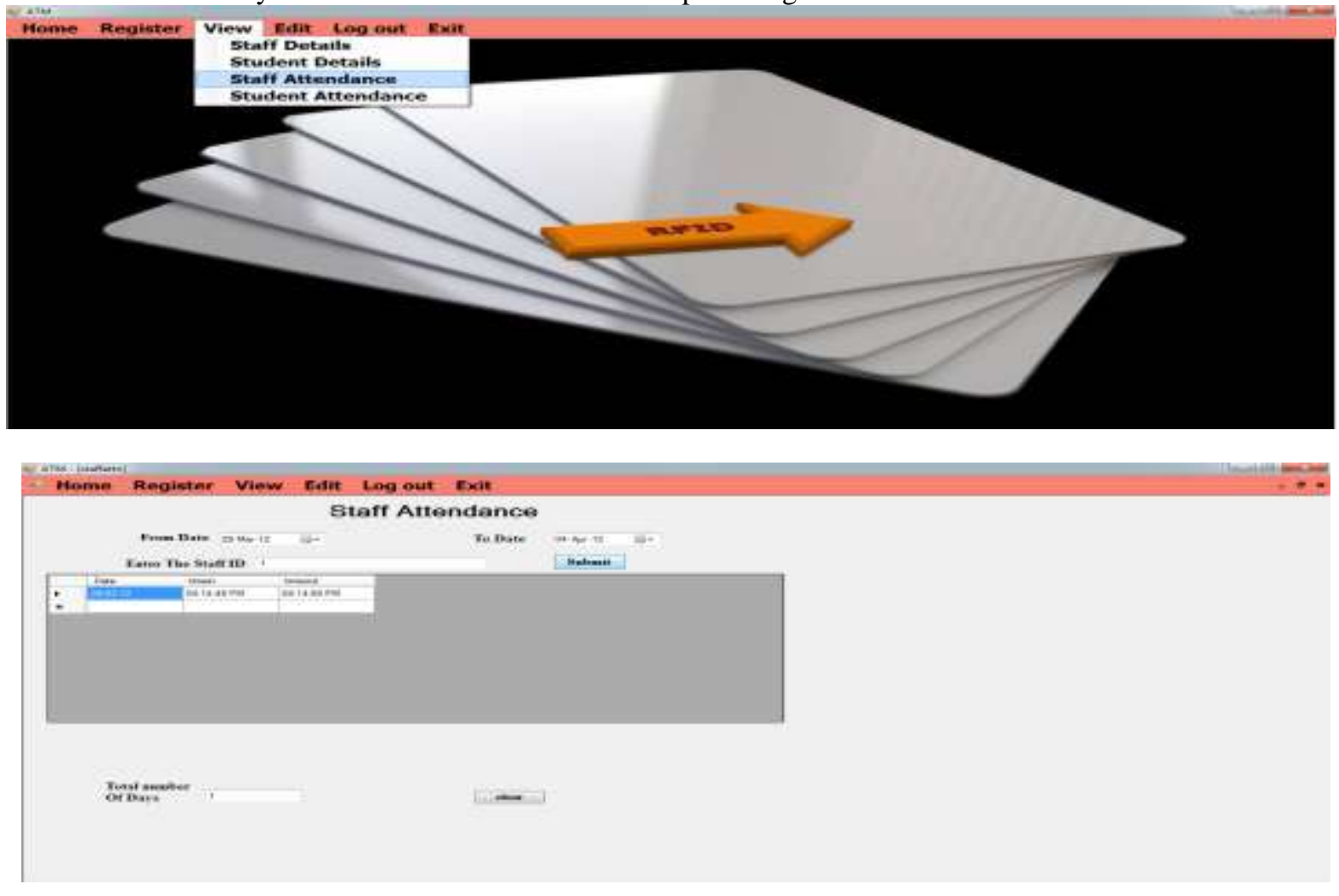


\section{Conclusion}

The objective of this project that is "A RFID based Employee attendance tracking system" was to design a system based on RFID technology that will not only change the hectic manual attendance procedure but also automate user's office. The final design of the project accomplished the idea of multinode environment which is responsible for automatic attendance and office automation according to the personalized profile of the RFID card holder. The design also deals with the issues (reliable data transfer) of multinode environment. To make sure reliable data transfer between server and reader node the project adopts CSMA/CD algorithm. This project facilitates the users in numerous ways like time saving in attendance procedure, security, employees' attendance management and many more.

1] The complete Reference Visual Basic.NET

\section{References}

[2] System Analysis and Design - Alias M. Awad

[3] Foundations of SQL Server 2008 R2 Business Intelligence - Guy Fouche, Lynn Langit

[4] Sql Server 2008 R2, Black Book - Kogent

[5] All datasheets from www.datasheetcatalog.com

[6] The helping Website

$\checkmark$ www.microsoft.com

$\checkmark \quad$ www.w3schools.com

$\checkmark \quad$ www.dotnetspider.com

$\checkmark \quad$ www.sql-tutorial.net

$\checkmark \quad$ http://www.wikipedia.org/

[7] Database Systems - Carolyn Begg

[8] http://en.wikipedia.org/wiki/ZKframework

[9] http://www.zkoss.org/Steps/discover.dsp

[10] http://www.zkoss.org/Steps/learn.dsp

[11] www.flipcart.com

[12] C\# Bible - Jasan Beres

[13] Qinghui Lin, B. W. Kwan, L. J. Tung, "RFID using attendance tracking ", Systems, Man and Cybernetics, 1997. Computational Cybernetics and Simulation, 1997 IEEE International Conference. 